Sellers, E. M., Naranuo, C. A., Harrison, M., et al (1983) Dlazepam loading. Simplified treatment of alcohol withdrawal. Clinical Pharmacological Therapy. 34. $822-826$.

Suluvan, J. T., SYKora, K., SchineIDERMAN, J., et al (1989) Assessment of alcohol withdrawal: the revised clinical institute withdrawal assessment for alcohol scale (CIWA-Ar). British Joumal of Addiction, 84, 1353-1357.

Wasnewsk, D., Matsumoto, H., KUR, E., et al (1996) Assessment of diazepam loading dose therapy of delirium tremens. Alcohol and Alcoholism, 31, 273-278.

ZELDA SUMMERS, DAVID WILLIAMS and ANDREW J. MCBRIDE, Cardiff Community Healthcare, Whitchurch Hospital, Cardiff

\section{Request for information}

Sir: Having recently survived aortic valve replacement surgery, I would be very interested to correspond with any colleague psychiatrist who has experienced cardiopulmonary by-pass surgery, and the particular psychopathological symptoms associated with this procedure.

D. M. HAMBRIDGe, Consultant Psychiatrist, Mental Health Resource Centre, Denton House, Northwich, Cheshire CW9 7LU

\title{
Mental Health Care in China
}

$$
\text { 中 國的 精 神 保 健 制 度 }
$$

\section{State Policies, Professional Services and Family Reponsibilities by Veronica Pearson}

This book traces the development of psychiatric services in the People's Republic of China. Historical, policy and legal frameworks are constructed to provide a context in which psychiatric services may be better understood. The experience of both staff and patients in one particular hospital is examined in detail. The book raises questions about the similarities in the experience of psychiatric illness across significantly different cultures.

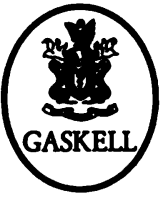

\section{$\bullet £ 12.50 \bullet 218 p p . \bullet 1995 \bullet$ ISBN 0902241745}

Available from bookshops and from the Publications Department, Royal College of Psychiatrists, 17 Belgrave Square, London SW1X 8PG (Tel. 0171-235 2351, extension 146) 